\title{
ARTICIE Alcohol policy and public health
}

\author{
Jason Luty
}

Jason Luty is a consultant in addictions psychiatry at Borders Health, Borders Addiction Service, Galashiels, UK.

Correspondence Dr Jason Luty, Borders Health, Borders Addiction Service, The Range, Tweed Road, Galashiels TD1 3EB, UK. Email: jason.luty@yahoo.co.uk

\begin{abstract}
SUMMARY
Alcohol is the most commonly used recreational drug in the world and the third leading cause of preventable death. Alcohol consumption and alcohol problems have increased steadily over the past six decades. Methods likely to reduce alcohol problems (e.g. minimum pricing, restricting licensing hours and increasing the availability of alcohol treatment) tend not to be supported by the drinks industry. Methods favoured by the industry (e.g. public education, industry self-regulation and product warning labelling) are less effective or do not work. The recent history of alcohol policy clearly demonstrates how the financial power of industry can influence governments and undermine effective public health measures, for instance by lobbying, political donations, confusion marketing and creating financial vested interests by grants from industry-sponsored 'social aspect organisations'.
\end{abstract}

\section{LEARNING OBJECTIVES}

- Recognise the overwhelming social, economic and health damage caused by alcohol misuse

- Recognise that measures such as taxation, minimum pricing and reducing availability are some of the most effective means of reducing alcohol problems

- Understand the mechanisms used by the drinks industry and other vested interests that influence the political process around alcohol regulation

\section{DECLARATION OF INTEREST}

None

Alcohol is the most common recreational drug in the world, having been used in most cultures over the past 8000 years. Almost all countries now have laws regulating the production and consumption of alcohol. The global alcoholic beverage market is worth around US\$1 trillion.

There seems to have been a generation of sobriety between the world wars, with drinking returning to typical levels gradually since the Second World War. (Box 1 recounts a short history of US Prohibition 1920-1933.) Alcohol consumption in the UK fell from around 11 litres of pure alcohol per annum per capita in 1900 to a low of around 4 litres in the 1920s. It has more than doubled since the 1950s to around 10 litres per capita in 2005
(World Health Organization (WHO) 2000; Easton 2010; Berridge 2013). A similar pattern is seen in the USA (Grant 1985).

\section{Prevalence of alcohol problems}

It is estimated that alcohol causes 2.5 million preventable deaths per year worldwide. Alcohol is the third leading cause of death in the USA $(85000$ deaths per year; Mokdad 2004) and, worldwide, alcohol is the third leading risk factor for the total burden of disease (Lim 2012). In the UK, alcohol causes 8700 deaths and 1.2 million hospital admissions, at a cost of $£ 21$ billion per annum (Brown 2014).

Developing countries have a disproportionately higher disease burden per litre of alcohol than Western countries and this is predicted to increase (Anderson 2009). Developing countries also have higher rates of alcohol problems per capita and fewer resources to address these (Anderson 2009). There is a close relationship between average alcohol consumption and alcohol-related problems, and binge drinking contributes disproportionately to alcohol-related mortality in lower-income countries (Blakely 2004).

In low doses (e.g. $10 \mathrm{~g}$ every other day, equivalent to one-third of a pint of beer per day), alcohol may actually be cardioprotective (Corrao 2000). However, doubt remains as to the effect of confounding factors on these findings, such as the tendency of people with chronic illness to abstain completely (Fillmore 2007; Chikritzhs 2009). Alcohol promotes cardiovascular disease at high doses, especially when consumed in irregular binges (Taylor 2008; Anderson 2009). Alcohol misuse increases the risk of liver cirrhosis, cancer, sexually transmitted diseases (including HIV), tuberculosis, alcoholic dementia, fetal alcohol syndrome and cardiovascular disease (Lim 2012). Whereas mortality from most other diseases has fallen, there has been a four-fold rise in deaths from alcohol-related liver disease in the UK since the 1970s. These deaths accounted for over $80 \%$ of the 7000 alcohol-related deaths in 2011 in the UK (Office for National Statistics 2013). However, medical reviews often overlook the overwhelming social problems commonly associated with alcohol misuse, including acquisitive and violent crime, job loss, accidents at work, road traffic accidents, 
child abuse and neglect, domestic violence, suicide, homicide and rape (Anderson 2009).

\section{Alcohol, family problems and crime}

There are several comprehensive surveys of the links between alcohol use, violence and crime in the UK (English 1995; Single 1998; Rehm 2006; Meier 2008). Recent alcohol intoxication affects either the victim or the perpetrator in $25 \%$ to $50 \%$ of violent incidents (including 60\% of homicides). For example, in Scotland one in every eight violent incidents occurred in or around pubs or clubs where alcohol was available. Alcohol was also involved in the majority of assaults (72\%) and incidents of domestic violence (62\%) (ISD Scotland 2011).

A UK Home Office study calculated that young adults who often got drunk were 5.5 times more likely to commit a violent offence than others (Richardson 2003). The 2003 Offending, Crime and Justice Survey found that although binge drinkers comprised $6 \%$ of the overall adult sample, they accounted for $30 \%$ of all crimes reported and $24 \%$ of all violent incidents (Matthews 2005). Alcohol misuse is involved in 25-33\% of cases of child abuse (Institute of Alcohol Studies 2014). Marriages in which one or both partners have an alcohol problem are twice as likely to end in divorce, and one in three divorce petitions in the UK cite excessive drinking by a partner (Prime Minister's Strategy Unit 2003).

\section{Economics of alcohol}

Over the past three decades, the price of alcohol has fallen dramatically in real terms. Alcohol is $61 \%$ more affordable in Britain today than in 1980, as real incomes have increased (Brown 2014). A bottle of whisky currently retailing at $£ 10$ would cost the equivalent of $£ 65$ if the price was adjusted for real earnings in the mid-1970s. 'Off-sales' is a term used to describe the sale of alcoholic beverages for consumption off the seller's premises. Off-sales now account for over two-thirds

B0X 1 Prohibition in the USA (1920-1933)

'Prohibition' refers to the 1920 banning of the production, transport and sales of all forms of alcohol for consumption in the USA. Prohibition, however, was repealed on 5 December 1933, and alcohol consumption eventually returned to pre-Prohibition levels after the Second World War (Blocker 2003; Blum 2010).

It is thought that Prohibition was possible in the USA because the political establishment was relatively new and not under the influence of the alcohol industry to the same extent as in European countries (where the temperance movement was also active, although beginning to decline by the early 20th century). Prohibition was strongly promoted by the Protestant churches and other diverse groups. The American Temperance Society was established in 1826 and had 1.5 million members by 1936 . The Prohibition Party was founded in 1868 and the Women's Christian Temperance Movement established in 1873. Both promoted the 'dry crusade' to prevent the abuse of women by drunken husbands. Ironically, alcohol was widely used in medical practice and US physicians lobbied against Prohibition. Perhaps not surprisingly, Winston Churchill stated that Prohibition was 'an affront to the whole history of mankind'.

Before Prohibition, the Wartime Prohibition Act of 1918 restricted sales of spirits, with the intention of reserving grain for the war effort. Alcohol consumption was actively discouraged to allow armament production. Voting rights for US women were established in 1920, and women tended to support prohibition. Prohibition might, therefore, have been a sop to the newly enfranchised women voters.

Paradoxically, Prohibition created a social climate whereby otherwise law-abiding people (such as policemen and judges) would tolerate illicit activity and/or seek out alcohol. By 1925, there were an estimated 30000-100000 'speakeasys' (illegal bars) in New York alone. Alcohol consumption was estimated to have dropped by only $40 \%$ of pre-Prohibition levels. Many citizens regarded the law as 'arbitrary and unnecessary' and it never received general public support. Prohibition unfairly targeted the working class, who had to remain dry while wealthy people could stockpile a cellar full of liquor. (In 1921, President Woodrow Wilson moved his own stockpile of alcohol out of the White House so that his successor, President Harding, could move his own in!) In 1930, the famous bootlegger George Cassidy claimed that $80 \%$ of congressmen and senators drank during Prohibition. Great profits in alcohol sales were generated by organised crime syndicates (the Mafia), which led to the widespread corruption of politicians and law-enforcement agencies. Ultimately, criminal gangs, such as the Capone family in Chicago, engaged in assassinations on the streets to eliminate competitors from the lucrative trade. Crimes increased by approximately $25 \%$, with a $12 \%$ increase in homicides and battery. The alcohol trade was estimated to be worth US $\$ 3$ billion per year during Prohibition (equivalent to US\$90 billion in 2010).
To prevent the consumption of industrial alcohol, the US government ordered manufacturers to poison ethanol with methyl-alcohol. Up to 10000 people may have died during Prohibition from drinking methylated alcohol (Blum 2010). As it was easier to smuggle spirits (rather than beer or wine) and to manufacture these at home, the consumption of spirits increased. In the first 10 years of Prohibition, enforcement costs for the US Bureau of Prohibition increased four-fold, reaching US\$13 million in 1930 (equivalent to around US\$320 million in 2010), with roughly equivalent spending by the US Coast Guard.

Prohibition was repealed on December 5, 1933. Large alcohol retailers quickly dominated the market and illicit alcohol sales and production almost disappeared. However, Prohibition also led to the decline of self-help groups for alcoholics, whose consumption had been severely reduced.

In 1932, the banking tycoon J. D. Rockefeller wrote:

'When Prohibition was introduced, I hoped that it would be widely supported by public opinion and the day would soon come when the evil effects of alcohol would be recognized. I have slowly and reluctantly come to believe that this has not been the result. Instead, drinking has generally increased; the speakeasy has replaced the saloon; a vast army of lawbreakers has appeared; many of our best citizens have openly ignored Prohibition; respect for the law has been greatly lessened; and crime has increased to a level never seen before' (0krent 2003: pp. 246-7). 
of alcohol consumption in the UK (ISD Scotland 2011). There has been a massive increase in offsales, which are made usually from supermarkets. In addition, $64 \%$ of all cheap off-trade alcohol is consumed by harmful drinkers, compared with only $9 \%$ by moderate drinkers (Meier 2008). It is estimated that $75 \%$ of the profits of alcohol companies come from sales to hazardous and harmful drinkers (Gornall 2014a).

The Organisation for Economic Co-operation and Development estimates that alcohol misuse costs the UK $2-3 \%$ of its gross domestic product annually ( $£ 12$ per week or $£ 625$ per year per person) (Anderson 2006; Office for National Statistics 2013; WHO 2014). In the UK, alcohol causes 8700 deaths and 1.2 million hospital admissions annually, at a cost of over $£ 21$ billion ( $£ 2.7$ billion in National Health Service (NHS) costs, $£ 11$ billion in criminal justice costs and $£ 7.3$ billion in lost productivity; Brown 2014). This greatly exceeds the $\sim £ 10$ billion generated in tax on alcohol (Daily Mail 2013; Office for National Statistics 2013). Surprisingly, alcohol taxes are generally below their maximum revenue-producing potential (Anderson 2008). These so-called 'externalities' (the additional societal cost of a product not borne by the manufacturer) - for example, crime, lost productivity, accidents and multiple health costs - are rarely publicised (Rehm 2009).

Consumption of illicit alcohol is a major health problem in lower-income countries. This could be countered by a tax system that encourages loweralcohol products, such as beer, along with rigorous enforcement including tax stamps to indicate duties have been paid (Parry 2003). Around a third of alcohol consumption worldwide is from illicit sources although this occurs disproportionately in lower-income countries.

\section{Effective strategies to reduce alcohol problems}

Methods that are likely to reduce alcohol problems include increasing price (especially minimum pricing), restricting licensing hours for alcohol sales, restricting the density of outlets, restricting age of purchase, reducing the drink-driving bloodalcohol limit, banning alcohol advertising and increasing the availability of alcohol treatment (Babor 2003; Anderson 2009). Methods that are less effective, or do not work, tend to be those supported by the industry: education and public health campaigns (especially in schools), voluntary self-regulation by the industry (Department of Health 2010; Mathews 2013; Bosque-Prous 2014) and product labelling with warnings (Babor 2003; Crombie 2007; Zeigler 2009).
An extensive review from The Lancet (Anderson 2009) makes uncomfortable reading for politicians and the drinks industry:

'Systematic reviews and meta-analyses show that policies regulating the environment in which alcohol is marketed (particularly its price and availability) are effective in reducing alcohol-related harm [...] However, school-based education does not reduce alcohol-related harm [...] Making alcohol more expensive and less available, and banning alcohol advertising, are highly cost-effective strategies to reduce harm'.

The disappointingly small effect of school and public education programmes on rates of alcohol problems might be due to the inability of health education programmes to compete with sophisticated mass-media marketing and advertising campaigns. In addition, attitudes towards and use of alcohol are determined primarily by the family and peer group (Jones 2007; Petrie 2007). Unlike tobacco products, warning labels on alcohol packaging are ineffective (Anderson 2009). See Box 2 for a comparison of alcohol and tobacco regulation.

Young people are particularly vulnerable to alcohol problems. Increasing the age of legal alcohol purchase and reducing the density of outlets are particularly effective at reducing alcohol consumption in young people (Wagenaar 2000, Huckle 2008). Policies that increase alcohol prices delay the start of drinking, slow young people's progression towards drinking large amounts, and reduce young people's heavy drinking and the volume of alcohol consumed per occasion (Cook

B0X 2 Why does the regulation of tobacco differ from regulation of alcohol?

- Smoking tobacco does not cause intoxication.

- The problems of tobacco smoking are almost entirely borne by the smoker - there are relatively few externalities such as crime and social disruption.

- Tobacco (nicotine) addiction has traditionally occurred at much higher rates than addiction to intoxicants like alcohol.

- The problems of tobacco smoking were only realised with prospective studies in the 1950s, whereas alcohol and other drugs have been condemned for centuries.

- Most importantly, changes in government policy are led by public opinion. In the USA, the public opinion changed to support the legalisation of cannabis (Pew Research Centre 2014), and voters in several states have approved the sale and recreational use of marijuana by adults. Public opinion now accepts that smoking is a health hazard, but attitudes towards alcohol have not changed significantly. 
2007). A systematic review of training bar staff to identify customers with alcohol problems and to promote responsible drinking revealed that it has little effect unless backed up by police enforcement and licence inspectors (Ker 2006).

Market-based interventions, such as blanket advertising bans on alcohol products and restricting times during which alcohol can be sold, are estimated to have a cost-effectiveness of US\$500-1000 per disability-adjusted life-year, although these interventions must be rigorously enforced (Anderson 2009).

A meta-analysis of nine studies in the USA reported that reducing the threshold for legal driving to a concentration of $0.8 \mathrm{~g} / \mathrm{L}$ alcohol in the blood resulted in a 7\% decrease in alcohol-related deaths in road traffic accidents (Mann 2001; Anderson 2009). Scotland, with one of the highest cirrhosis rates in Europe, reduced the drinkdriving blood-alcohol limit from $80 \mathrm{mg} / 100 \mathrm{~mL}$ blood to $50 \mathrm{mg} / 100 \mathrm{~mL}$, in line with many European countries, in late 2014. The higher limit remains in place in England.

Random alcohol testing and mandatory alcohol testing at sobriety check-points are also effective (Shults 2001). Driver-related alcohol interventions such as these are estimated to have a cost-effectiveness of US\$700-1200 per disability-adjusted life-year (Anderson 2009). A meta-analysis of 215 studies of mandatory drinkdriving programmes reported a reduction in recurrence of alcohol-related driving offences and accidents of 8-9\% (Wells-Parker 1995; Anderson 2009). Designated driver schemes, however, are not effective (Ditter 2005).

Observations following changes in alcohol price and taxation in the single market of European countries consistently show that reduction in price leads to increased consumption and alcohol-related problems (Rabinovich 2009). A meta-analysis of 112 studies (Wagenaar 2009) reported overall price elasticity for all alcoholic beverage types of -0.52 in the short term and -0.82 in the long term. In other words, a $10 \%$ increase in price produces a $5 \%$ reduction in short-term consumption and an $8 \%$ reduction in long-term consumption. Reductions in consumption in response to price increases are lower for beer than for wine or spirits (price elasticity -0.46 for beer, -0.69 for wine and -0.80 for spirits; Wagenaar 2009). Price-based measures to reduce consumption are estimated to have a cost-effectiveness of US $\$ 500$ per disabilityadjusted life-year (Anderson 2009).

Brief interventions from health professionals are one of the most cost-effective means of reducing alcohol-related harm, although there is no advantage in using more prolonged psychological treatment in primary care (Kaner 2007). Brief interventions are estimated to have a costeffectiveness of US\$2000-4000 per disabilityadjusted life-year (Anderson 2009). Unfortunately, brief interventions, unlike increased taxation, are costly and slower to implement, as they require the training of substantial numbers of health professionals.

\section{Effective industry strategies to prevent restrictions on alcohol}

There is a certain irony to the fact that the headquarters for the alcohol manufacturer Diageo's flagship distillery in Fife is immediately adjacent to the base for the NHS Community Alcohol and Drug Team at the Cameron Hospital, Leven. After a visit to the distillery in Fife, the then Prime Minister David Cameron referred to whisky as 'an iconic product with a rich heritage and a fantastic future' (Collin 2014). The alcohol industry is the example par excellence of how powerful corporations can lobby governments and influence policy to promote their products, irrespective of public health, social order and economic reality (Babor 2013). The UK is home to two of the largest alcohol multinationals, Diageo (producers of Johnnie Walker, Smirnoff and Guinness) and SABMiller (producers of Carling).

\section{Targeting unregulated markets}

The traditional markets for alcohol in developed countries are probably saturated, leaving developing countries as targets for aggressive marketing campaigns, especially South America, Africa and South East Asia. Sales in developing countries were expected to exceed those for developed nations by 2015 (Casswell 2009). Lower-income countries suffer higher mortality and morbidity from alcohol, and lack the resources to enforce the alcohol regulations that they might have devised. These regulations (and alcohol taxes) are also much less stringent than in developed countries. In addition, large multinationals use sophisticated, well-funded marketing strategies to target 'under-consuming' women (Caetano 2006; Casswell 2009; Gornall 2014a).

\section{Regulatory capture: lobbying and the involvement of the alcohol industry in regulation}

Attempts by powerful vested-interest groups to influence and avoid restrictive regulations (known as 'regulatory capture') are well recognised by economists. The dominant multinational corporations within the alcohol industry can place 
great pressure on governments, especially in lowerincome countries (Miller 2010; Lyness 2014). The UK government's 2004 Alcohol Harm Reduction Strategy for England (Department of Health 2004) and its 2013 decision to abandon minimum pricing were strongly criticised for promoting ineffective policies following the influence of the alcohol industry. In 2013, over 500 heads of public health organisations wrote to the WHO to express the view that the alcohol industry should have no role in devising public health policies (Babor 2013).

The Expert Committee on Problems Related to Alcohol Consumption, from the WHO (2007), recommended an analysis of the feasibility of 'international mechanisms, including legally binding agreements,' proposing a Framework Convention on Alcohol Control. However there has been no such convention in the 7 years since the initial calls for its creation (Zeigler 2013). A global Framework Convention on Tobacco Control was agreed in 2003, but only after years of delay after lobbying from the tobacco industry. However, alcohol consumption is more widely established than tobacco: approximately 80\% of the population drink occasionally (WHO 2010). Abstinence is not a necessary or popular option for most people who consume alcohol (unlike tobacco). The WHO (2010) recommends increasing taxation, restricting availability and the cessation of advertising of alcohol.

An alternative convention was announced in 2012 by the drinks industry-funded International Centre for Alcohol Policies (ICAP). This organisation endorsed seemingly credible but actually ineffective policies, such as self-regulation of marketing and the promotion of 'responsible drinking' (Chan 2013). The use of industrysponsored 'front groups' such as ICAP, Portman Group and DrinkWise is a common tactic. These superficially independent expert groups promote policy options that are ineffective and delay effective regulation (Caetano 2008; Casswell 2009; Babor 2013; Mathews 2013; Gornall 2014b). The alcohol industry successfully lobbied to delay the introduction of mandatory health warnings on alcoholic drink containers by 2 years in Australia (Mathews 2013). Tactics included making political donations, disputing evidence that reducing consumption has public health benefits, prolonging consultation periods to consider weak evidence and creating their own voluntary code. Such voluntary codes are often ignored (Department of Health 2010; Mathews 2013).

The alcohol industry has been shown to be closely involved in the creation of alcohol policies despite the obvious conflict of interests
(Giesbrecht 2000; Anderson 2008; Endal 2008; Hill 2008; Casswell 2009). The industry opposes alcohol taxation, restrictions on availability and advertising, and it actively promotes ineffective policies such as training bar staff, industry selfregulation and nominated driver schemes.

Many of the most effective means of reducing alcohol-related harms have been abandoned in Western countries over the past 20 years as a result of free-trade agreements and governments bent on deregulation, despite the fact that some countries have been able to exclude alcohol and tobacco from their free-trade policies (Hall 2005; Crombie 2007).

Not surprisingly, powerful professional lobbying from the alcohol industry has been used in support of free-trade agreements (Zeigler 2009). Lobbying by the alcohol industry is thought to have resulted in the removal of tariffs and regulations from alcohol sales in Chile, South Korea, the Philippines and India - notionally to remove restrictive market regulations on the grounds that they are an 'unnecessary interference in trade' (Collin 2014). Removal of these trade restrictions was promoted as a requirement to join free trade organisations such as the World Trade Organization and the European Union.

The alcohol industry and industry-funded 'social aspect organisations' in California spent US $\$ 3$ million on lobbying and $\$ 3.5$ million on political donations in 2007 (Marin Institute 2008). The aforementioned Diageo and SABMiller fund responsible-drinking campaigns aimed at teenagers, despite evidence of their ineffectiveness (Casswell 2009). Indeed, some evidence suggests these campaigns actually promote drinking rather than reduce it (Smith 2006; Caetano 2008; Casswell 2009; Gornal 2014c).

\section{Confusion marketing}

Confusion marketing is the selling of products or services in a way that deliberately confuses the consumer. In the alcohol industry, this involves promoting mixed and confusing health messages.

\section{Misuse $v$. dependence}

The conventional distinction between 'dependence' (probably used synonymously with the lay term 'alcoholism') and 'misuse' (including 'binge drinking') has recently been abolished by professional groups. The new diagnostic criteria in DSM-5 remove the distinction between substance dependence and misuse, creating a continuum (American Psychiatric Association 2013). Dependence is characterised by a physical withdrawal syndrome, and severity of misuse is determined by the number of clinical features from 
2 (mild) to 6 or more (severe). Although there is good rationale for these changes, they are likely to create yet more confusion for the general public.

Sensible drinking limits and alcohol content

The quantity of alcohol contained in a notional 'standard drink' or 'unit of alcohol' varies between countries. It is $7.62 \mathrm{~mL}(6 \mathrm{~g})$ of alcohol in Austria, $25 \mathrm{~mL}(19.75 \mathrm{~g})$ in Japan, $18 \mathrm{~mL}(13.7 \mathrm{~g})$ in the USA, and $10 \mathrm{~mL}(7.6 \mathrm{~g})$ in the UK.

The alcohol content of drinks is conventionally stated as percentage of alcohol by volume - that is, the millilitres of pure alcohol in $100 \mathrm{~mL}$ of beverage, rather than number of units per glass, bottle or can. It is beyond the ability of most people to easily calculate the alcohol content of a pint of $5 \%$ beer. To add to the confusion, alcohol content has traditionally been referred to as 'proof', an archaic reference to the concentration required to support combustion of gunpowder.

In the UK the maximum 'safe' daily consumption of alcohol is also confused. The NHS states that men 'should not regularly drink more than 3 to 4 units a day', compared with 2 to 3 units for women (Change4Life 2015). The Royal College of Physicians (1987) advises men to consume no more than 21 units of alcohol per week and women no more than 14 units per week, although a recent draft of guidelines from the Department of Health (2016) advises maximum sensible drinking of 14 units per week for both genders.

\section{Creating financial vested interests: grants and sponsorship}

Five UK charities are funded directly by the alcohol industry. The Diageo Foundation is a charity funded entirely by the alcohol industry (Diageo) that gave out 528 grants in 2012, including grants to Cancer Research UK and Harm Reduction International (Lyness 2014). Two charities, Mentor and Addaction, have received large grants from the alcohol industry, and this might have influenced their decision to remain members of the UK government's alcohol network when most other health agencies resigned in protest against the government's decision to abandon minimum pricing (Miller 2010; Gornall 2014d). The alcohol industry uses donations and commissions projects to influence charities, and those charities in turn influence government policy (Lyness 2014).

Not-for-profit organisations, such as the Portman Group, are not charities and are not regulated in the same manner: in particular, they are not obliged to disclose their donors.

Sports sponsorship by alcohol companies is an obvious example of both indirect marketing and the creation of financial vested interests to prevent sales regulation (Gornall 2014c). The Brazilian government is suspected of abandoning its prohibition of alcohol in sports stadiums to placate the drinks industry in its bid for the 2014 World Cup. It has been said that 'Alcohol and sport are inextricably coupled. Alcohol sponsorship is essential to fund sporting events' (Godlee 2014a).

\section{Recent examples of industry influencing alcohol policy}

\section{The billion-unit pledge}

In March 2012, many of the largest alcohol producers in the UK promised to reduce alcohol sales by 1 billion units (2\%) by the end of 2015 by promoting low-alcohol products as part of a 'responsibility deal' between the industry and the government. The government minimum pricing promise was unveiled on the same day, but was abandoned a year later. The effectiveness of the billion-unit pledge was to be measured by the Responsibility Deal Alcohol Network. However, all but three of the network's non-industry members, including the Chair, resigned by March 2014 because 'transparency and trust in the process has been eroded by data being delivered inappropriately to the industry's Portman Group' (Brown 2015). Indeed, the majority of health groups resigned from the Responsibility Deal Alcohol Network even before it was publicly launched in March 2011. Nevertheless, despite the fact that the monitoring group for the billionunit pledge consists almost entirely of industry representatives, the pledge is one of the main policies in the government's Living Well for Longer plan (Department of Health 2013; Gornall 2014e).

\section{Abolition of the UK alcohol duty escalator}

Since 2008, UK alcohol duty has increased by $2 \%$ above the rate of inflation. However, the drinks industry lobbied for the abolition of the UK alcohol duty escalator, succeeding in March 2014. This led to the Chancellor at the time, George Osborne, being awarded the title 'beer drinker of the year' by the industry-funded All Parliamentary Beer Group, with the associated favourable, industrypromoted publicity.

\section{Minimum pricing}

Minimum pricing involves setting a floor price per unit of alcohol, below which it is illegal to sell alcohol beverages. Alcohol-related harm is directly related to dose and consumption is partly determined by price, particularly for heavy drinkers (Stockwell 2014). It is estimated that the 
majority of alcohol problems arise from a small minority of heavy drinkers $(80 \%$ of consumption occurs in $20 \%$ of users, known as the Pareto principle). A 2008 alcohol strategy consultation document from the Department of Health (2008) stated that drinkers who regularly drank at levels above recommended limits were responsible for $76 \%$ of UK alcohol consumption. As previously mentioned, the majority of the profits of alcohol companies (and alcohol tax revenues) come from sales to hazardous and harmful drinkers (Gornall 2014a).

Sheron and colleagues (2014) estimated that a minimum price of 50p per unit of alcohol would reduce consumption in harmful drinkers around 200 times more than in low-risk drinkers. People drinking the equivalent of 4 bottles of spirits (120 units) per week spend 33p per unit, regardless of income, whereas moderate drinkers spend around $£ 1.10$ per unit; $80 \%$ of alcohol is consumed at home (off-sales) by heavy drinkers. With a minimum unit price of 50p, heavy drinkers would have to pay around $13 \%$ of their income to maintain their heavy consumption levels (compared with $0.03 \%$ of income for moderate drinkers to maintain their consumption). Minimum unit pricing would not affect sales in bars and restaurants, as virtually all sales in these venues exceed the minimum price. It has been estimated that a minimum unit price of 40p would save around 1000 lives and result in 50000 fewer crimes per year in England (Meier 2008; Meng 2013).

Canada was the first county to introduce minimum pricing, and has benefitted from a significant reduction in alcohol-related harms. The Canadian government, however, introduced minimum pricing to protect revenue rather than to improve public health (Stockwell 2014). Therefore, the Canadian drinks industry supported minimum pricing, in contrast to the vehement opposition observed in Europe.

Below-cost selling, or selling alcohol for less than the value of tax paid on the beverage, has been prohibited by the UK government. However, this affects only $0.7 \%$ of the UK market, compared with $23 \%$ for a $45 \mathrm{p}$ minimum unit price (Brennan 2014). In practical terms, the ban on belowcost selling prevents around 14 deaths and 500 hospital admissions annually in England, but a 45 p minimum unit price could prevent 624 deaths and 23700 admissions (Brennan 2014).

Minimum pricing was intended to be introduced around the same time in England and Scotland (HM Government 2012). However, it was abandoned in England on 17 July 2013, the day before the Parliamentary summer recess, nominally because there was not enough 'concrete evidence' that it would not penalise responsible drinkers and low-income families (Gornall 2014d). There was also concern about a drop in tax revenues. Numerous private conversations took place between ministers and representatives of the drinks industry and major supermarket chains (the principal retailers of off-sale alcohol) in the months prior to this decision, which was highly suggestive of skulduggery (Gornall 2014a,d).

Scotland is the first European country to attempt to introduce minimum pricing. Minimum pricing laws were planned to take effect in April 2014, having been passed by the Scottish Parliament in May 2012 (Gornall 2014d). Scotland has the highest rate of cirrhosis mortality in Europe and alcohol (primarily spirits) became $62 \%$ more affordable between 1980 and 2005. There is widespread international opposition (based on free-trade arguments) from the drinks industry, which fears that creating a precedent of minimum pricing will encourage other European countries to introduce minimum pricing (similar to the spread of smoking bans after smoking in public spaces was banned in Ireland).

At the time of writing (July 2016), minimum pricing for alcohol has been delayed in Scotland, and was abandoned in the rest of the UK in July 2013, presumably because of legal challenge and lobbying from the drinks industry, despite overwhelming evidence for its effectiveness (Babor 2003; Meier 2010; Barnes 2013; Maddox 2013; Godlee 2014b). The alcohol industry, represented as the Scotch Whisky Association, had been performing 'massive lobbying' over the summer of 2012. By contrast, the industry's attempt to block minimum pricing in the Scottish courts was overturned on 3 May 2013 in the ruling that 'none of the challenges to the minimum pricing measures is well founded' (Gornall 2014d).

The European Court of Justice heard the case against minimum pricing in early 2016 on the basis of the petition that minimum pricing in Scotland 'would artificially distort trade in the alcoholic drinks market' (McCambridge 2014). The European Court suggested that minimum pricing was a 'disproportionate' way of tackling Scotland's alcohol problems, but ultimately referred the case back the Scottish Court to rule whether tax increases would be a more effective or 'proportionate' measure. Whether this will lead to a further legal challenge in the European Court of Justice remains to be seen. The case continues (Nicholson 2016).

Minimum pricing in Scotland may have been promoted because the Scottish Parliament is a 
recent institution, having been established in 2000. The unhealthy relationship between established political parties and the drinks industry had not been created in Scotland. This is surprising, as income from the drinks industry ranks second only to oil in the Scottish economy. It might be that the Scottish National Party has been largely ignored by the drinks industry until very recently and has not been influenced by industry lobbying, in comparison with the established political parties in London. By contrast, there are four allparty parliamentary groups in the UK parliament notionally created to support the interests of the beer, wine, spirits and cider industries in Westminster. The beer group contains 300 Members of Parliament, almost half of the House of Commons.

\section{Conclusions}

The alcohol industry aggressively uses all available political, legal and public relations strategies to obstruct any restrictions on alcohol sales. These include targeting unregulated markets, regulatory capture, government lobbying, confusion marketing, grants and sponsorship as part of marketing campaigns and public relations activities and creation of vested interests, including grants to charities. Minimum pricing in Scotland is currently the highest profile activity on the international alcohol policy agenda and, having failed to prevent this using lobbying and other less dramatic tactics, the alcohol industry has shown no hesitation in aggressively delaying the adoption of this policy by extraordinarily expensive legal challenges within national and international courts.

\section{References}

American Psychiatric Association (2013) Diagnostic and Statistical Manual of Mental Disorders (5th edn). APA

Anderson P, Baumberg B (2006) Alcohol in Europe. Institute of Alcohol Studies.

Anderson P (2008) Consulting with the alcohol industry. Drug and Alcohol Review, 27: 463-65.

Anderson P, Chisholm D, Fuhr DC (2009) Effectiveness and costeffectiveness of policies and programmes to reduce the harm caused by alcohol. Lancet, 373: 2234-46.

Babor TF, Caetano R, Casswell S (2003) Alcohol: No Ordinary Commodity. Oxford University Press.

Babor T, Hall W, Humphreys K, et al (2013) Who is responsible for the public's health? The role of the alcohol industry in the WHO global strategy to reduce the harmful use of alcohol. Addiction, 108: 2045-7.

Barnes E (2013) Minimum-pricing: whisky industry's bid to end the deadlock. The Scotsman, 17 November.

Berridge V (2013) Demons: Our Changing Attitudes to Alcohol, Tobacco and Drugs. Oxford University Press.

Blakely T, Hales S, Kieft C, et al (2004) Distribution of risk factors by poverty. In Comparative Quantification of Health Risks: Global and
Regional Burden of Disease due to Selected Major Risk Factors (eds M Ezzati, AD Lopez, A Rodgers, et al). World Health Organization.

Blocker Jr JS, Fahey DM, Tyrrell IR (eds) (2003) Alcohol and Temperance in Modern History: An International Encyclopedia. ABC-CLIO.

Blum D (2010) The chemist's war: the little-told story of how the US government poisoned alcohol during Prohibition with deadly consequences. Slate, 19 February (http://www.slate.com/articles/ health_and_science/medical_examiner/2010/02/the_chemists_war. html).

Bosque-Prous M, Espelt A, Guitart AM, et al (2014) Association between stricter alcohol advertising regulations and lower hazardous drinking across European countries. Addiction, 109: 1634-43.

Brennan A, Meng Y, Holmes J, et al (2014) Potential benefits of minimum pricing for alcohol versus a ban on below cost selling in England 2014. BMJ, 349: 13.

Brown K (2014) Be fair to us all, George: don't give in to industry by scrapping the alcohol duty escalator. BMJ, 348: 25.

Brown K (2015) The UK government's relationship with the alcohol industry. BMJ (http://blogs.bmj.com/bmj/2015/03/27/katherinebrown-the-uk-governments-relationship-with-the-alcohol-industry).

Caetano R, Laranjeira R (2006) A 'perfect storm' in developing countries: economic growth and the alcohol industry. Addiction, 101: 149-52.

Caetano R (2008) About smoke and mirrors: the alcohol industry and the promotion of science. Addiction, 103: 175-78.

Casswell S, Thamarangsi T (2009) Reducing harm from alcohol: call to action. Lancet, 373: 2247-57.

Change4Life (2015) Alcohol Units and Guidelines. Change4Life (http:// www.nhs.uk/change4life/Pages/alcohol-lower-risk-guidelines-units. aspx)

Chan M (2013) Doctors and the alcohol industry: an unhealthy mix? $B M J, 346: f 1889$

Chikritzhs T, Fillimore K, Stockwell T (2009) A healthy dose of skepticism: four good reasons to think again about protective effects of alcohol coronary heart disease. Drug and Alcohol Reviews, 28: 441-4.

Collin J, Johnson E, Hill S (2014) Government support for the alcohol industry: promoting exports, jeopardising global health? BMJ, 348: g3648.

Cook PJ (2007) Paying the Tab: The Costs and Benefits of Alcohol Control. Princeton University Press.

Corrao G, Rubbiati L, Bagnardi V, et al (2000) Alcohol and coronary heart disease: a meta-analysis. Addiction, 95: 1505-23.

Crombie IK, Irvine L, Elliott L, et al (2007) How do public health policies tackle alcohol-related harm: a review of 12 developed countries. Alcohol, 42: 492-9

Daily Mail (2013) Alcohol abuse 'costing Britain $£ 6 b n$ a year'. Daily Mail (10 December 2013) (http://www.dailymail.co.uk/news/article-19699/ Alcohol-abuse-costing-Britain-6bn-year.html).

Department of Health (2004) Alcohol Harm Reduction Strategy for England. Department of Health.

Department of Health (2008) Safe, Sensible, Social - Consultation on Further Action. Department of Health.

Department of Health (2010) Consultation on Options for Improving Information on the Labels of Alcoholic Drinks to Support Consumers to Make Healthier Choices in the UK. Department of Health.

Department of Health (2013) Living Well for Longer: A Call to Action to Reduce Avoidable Premature Mortality. Department of Health.

Ditter SM, Elder RW, Shults RA, et al (2005) Effectiveness of designated driver programs for reducing alcohol-impaired driving: a systematic review. American Journal of Preventive Medicine, 28: $280-7$. 


\section{MCO answers \\ $1 \mathrm{c} \quad 2 \mathrm{~d} \quad 3$ e $\quad 4$ e $\quad 5 \mathrm{c}$}

Easton M (2010) The myths of boozed-up Britain. BBC News (8 January 2010) (http://www.bbc.co.uk/blogs/legacy/thereporters/ markeaston/2010/01/alcohol.html).

Endal D (2008) Drinks Industry Supplanting Government Role in Alcohol Policies in Sub-Saharan Africa. ADD Resources (http://www. add-resources.org/drinks-industry-supplanting-government-role-inalcoholpolicies-in-sub-saharan-africa.4484341-76188.html).

English DR, Holman CDJ, Milne E, et al (1995) The Quantification of Drug-Caused Morbidity and Mortality in Australia. Commonwealth Department of Human Services and Health.

Fillmore KM, Stockwell T, Chikritzhs T, et al (2007) Moderate alcohol use and reduced mortality risk: systematic error in prospective studies and new hypotheses. Annals of Epidemiology, 17 (Suppl): S16-23.

Giesbrecht N (2000) Role of commercial interests in alcohol policies: recent developments in North America. Addiction, 95 (Suppl): 581-95.

Godlee F (2014a) Alcohol and sport. BMJ, 348: g3869

Godlee F (2014b) Minimum alcohol pricing: a shameful episode. BMJ 348: 110

Gornall J (2014a) Under the influence. BMJ, 348: f7646.

Gornall $J$ (2014b) Alcohol charities may have been influenced by funding from industry. BMJ, 348: g4042.

Gornall J (2014c) World Cup 2014: festival of football or alcohol? BMJ, 348: g3772.

Gornall J (2014d) Under the influence: Scotland's battle over alcohol pricing. $B M J, 348:$ g1274

Gornall J (2014e) Is the billion unit pledge just window dressing? BMJ, 348: g3190.

Grant BF, Colliver JD, National Institute on Alcohol Abuse and Alcoholism, et al (1985) US Alcohol Epidemiologic Data Reference Manual (vol 1). US Department of Health and Human Services, Public Health Service, Alcohol, Drug Abuse, and Mental Health Administration, National Institute on Alcohol Abuse and Alcoholism.

Hall W (2005) British drinking: a suitable case for treatment? BMJ, 331: $527-8$

Hill L (2008) The alcohol industry. In International Encyclopedia of Public Health (eds K Heggenhougen, S Quah). Academic Press.

HM Government (2012) The Government's Alcohol Strategy. TSO (The Stationery Office).

Huckle T, Huakau J, Sweetsur P, et al (2008) Density of alcohol outlets and teenage drinking: living in an alcogenic environment is associated with higher consumption in a metropolitan setting. Addiction, 103: 1614-21.

Institute of Alcohol Studies (2014) Alcohol, Domestic Abuse and Sexual Assault. Institute of Alcohol Studies.

ISD Scotland (2011) Alcohol Statistics Scotland 2011. ISD Scotland Publications (https://www.isdscotland.org/Health-Topics/Drugsand-Alcohol-Misuse/Alcohol/Historic-Publications/docs/AlcoholBulletin2011.pdf). Accessed 22 July 2016

Jones $\mathrm{L}$, James $\mathrm{M}$, Jefferson $\mathrm{T}$, et al (2007) A Review of the Effectiveness and Cost-Effectiveness of Interventions Delivered in Primary and Secondary Schools to Prevent and/or Reduce Alcohol Use by Young People Under 18 Years Old. NICE.

Kaner EFS, Beyer F, Dickinson HO, et al (2007) Effectiveness of brief alcohol interventions in primary care populations. Cochrane Database of Systematic Reviews, 2: CD004148.

Ker K, Chinnock P (2006) Interventions in the alcohol server settings for preventing injuries. Cochrane Database of Systematic Reviews, 2 : CD005244.

Lim SS, Vox T, Flaxman AD, et al (2012) A comparative risk assessment of burden of disease and injury attributable to 67 risk factors and risk factor clusters in 21 regions, 1990-2010: a systematic analysis for the Global Burden of Disease Study 2010. Lancet, 380: 2224-60.
Lyness SM, McCambridge J (2014) The alcohol industry, charities and policy influence in the UK. European Journal of Public Health, 24: $557-61$

Maddox D (2013) Minimum pricing: Scots go it alone after UK u-turn. The Scotsman (18 July 2013) (http://www.scotsman.com/news/ politics/top-stories/minimum-pricing-scots-go-it-alone-after-uk-uturn-1-3004593)

Mann RE, Macdonald S, Stoduto LG, et al (2001) The effects of introducing or lowering legal per se blood alcohol limits for driving: an international review. Accident Analysis and Prevention, 33: 569-83.

Marin Institute (2008) You Get What You Pay For: California's Alcohol Lobby. Marin Institute.

Mathews R, Thorn M, Giorgi C (2013) Vested interests in addiction research and policy. Is the alcohol industry delaying government action on alcohol health warning labels in Australia? Addiction, 108: 1889-96.

Matthews S, Richardson A (2005) Findings from 2003 Offending, Crime and Justice Survey: Alcohol-Related Crime and Disorder. Findings 261. Home Office.

McCambridge J, Hawkins B, Holden C (2014) Vested interests in addiction research and policy. The challenge corporate lobbying poses to reducing society's alcohol problems: insights from UK evidence on minimum unit pricing. Addiction, 109: 199-205.

Meier P (2008) Independent Review of the Effects of Alcohol Pricing and Promotion: Part B. Modelling the Potential Impact of Pricing and Promotion Policies for Alcohol in England: Results from the Sheffield Alcohol Policy Model. University of Sheffield (https://www.shef.ac.uk/ polopoly_fs/1.95621!/file/PartB.pdf).

Meier PS, Brennan A, Purshouse R (2010) Policy options for alcohol price regulation: the importance of modelling population heterogeneity. Addiction, 105: 383-93

Meng Y, Brennan A, Holmes J, et al (2013) Modelled Income GroupSpecific Impacts of Alcohol Minimum Unit Pricing in England 2014/15: Policy Appraisals using New Developments to the Sheffield Alcohol Policy Model (v2.5). University of Sheffield (http://www.shef.ac.uk/ polopoly_fs/1.291621!/file/julyreport.pdf).

Miller D, Harkins C (2010) Corporate strategy, corporate capture. Critical Social Policy, 30: 564-89

Mokdad AH, Marks JS, Stroup DF, et al (2004) Actual causes of death in the United States, 2000. JAMA, 291: 1238-45.

Nicholson S (2016) Why does Scotland still not have minimum pricing? BBC News (http://www.bbc.co.uk/news/uk-scotland-36463648). Accessed 27 July 2016

Office for National Statistics (2013) Statistical Bulletin: Alcohol-Related Deaths in the United Kingdom, 2011. ONS (http://www.ons.gov.uk/ peoplepopulationandcommunity/healthandsocialcare/causesofdeath/ bulletins/alcoholrelateddeathsintheunitedkingdom/2013-01-29)

Okrent D (2003) Great Fortune: The Epic of Rockefeller Center. Viking Press.

Parry C, Myers B, Thiede M (2003) The case for an increased tax on alcohol in South Africa. South African Journal of Economics, 71: 266-82

Petrie J, Bunn F, Byrne G (2007) Parenting programmes for preventing tobacco, alcohol and drug misuse in children $<18$ years: a systematic review. Health Education Research, 22: 177-91.

Pew Research Centre (2014) America's New Drug Policy Landscape. Pew Research Centre (http://www.people-press.org/files/legacypdf/04-02-14\%20Drug\%20Policy\%20Release.pdf).

Prime Minister's Strategy Unit (2003) Strategy Unit Alcohol Harm Reduction Project: Interim Analytical Report. Cabinet Office.

Rabinovich L, Brutscher P, De Vries H, et al (2009) The Affordability of Alcoholic Beverages in the European Union. Understanding the Link between Alcohol Affordability, Consumption and Harms. Rand Corporation 
Rehm J, Patra J, Popova S (2006) Alcohol-attributable mortality and potential years of life lost in Canada 2001: implications for prevention and policy. Addiction, 101: 373-84.

Rehm J, Mathers C, Popova S, et al (2009) Global burden of disease and injury and economic cost attributable to alcohol use and alcoholuse disorders. Lancet, 373: 2223-33.

Richardson A, Budd T (2003) Alcohol, Crime and Disorder: A Study of Young Adults. Home Office Research Study 263. Home Office Research, Development and Statistics Directorate.

Royal College of Physicians (1987) The Medical Consequences of Alcohol Abuse, A Great and Growing Evil. Tavistock Publications.

Sheron N, Chilcott F, Matthews L, et al (2014) Impact of minimum price per unit of alcohol on patients with liver disease in the UK. Clinical Medicine 14: 396-403.

Shults RA, Elder RW, Sleet DA, et al (2001) Reviews of evidence regarding interventions to reduce alcohol-impaired driving. American Journal of Preventive Medicine, 21: 66-88.

Single E, Robson L, Xie X, et al (1998) The economic costs of alcohol, tobacco and illicit drugs in Canada, 1992. Addiction, 93: 991-1006

Smith S, Atkin C, Roznowski J (2006) Are 'drink responsibly' alcohol campaigns strategically ambiguous? Health Communications, 20: 1-11.

Stockwell T (2014) Minimum unit pricing for alcohol. BMJ, 349: g5617.

Taylor B, Rehm J, Room R, et al (2008) Determination of lifetime injury mortality risk in Canada in 2002 by drinking amount per occasion and number of occasions. American Journal of Epidemiology, 168 1119-25.

Wagenaar AC, Toomey TL (2000) Alcohol policy: gaps between legislative action and current research. Contemporary Drug Problems, 27: $681-733$

Wagenaar AC, Salois MJ, Komor KA (2009) Effects of beverage alcohol price and tax levels on drinking: a meta-analysis of 1003 estimates from 112 studies. Addiction, 104: 179-90.

Wells-Parker E, Bangert-Drowns R, McMillen R, et al (1995) Final results from a meta-analysis of remedial interventions with DUI offenders. Addiction, 90: 907-26.

World Health Organization (2000) International Guide for Monitoring Alcohol Consumption and Related Harm. WHO.

World Health Organization (2007) Expert Committee on Problems Related to Alcohol Consumption: Second Report. WHO.

World Health Organization (2010) Global Strategy to Reduce Harmful Use of Alcohol. WHO.

World Health Organization (2014) Global Status Report on Alcohol and Health 2014 . WHO

Zeigler DW (2009) The alcohol industry and trade agreements: a preliminary assessment. Addiction, 104 (suppl 1): 13-26.

Zeigler D (2013) On delaying a Framework Convention on Alcohol Control: regrettably agreeing but calling for strategic action to accelerate the process. Addiction, 108: 457-9.

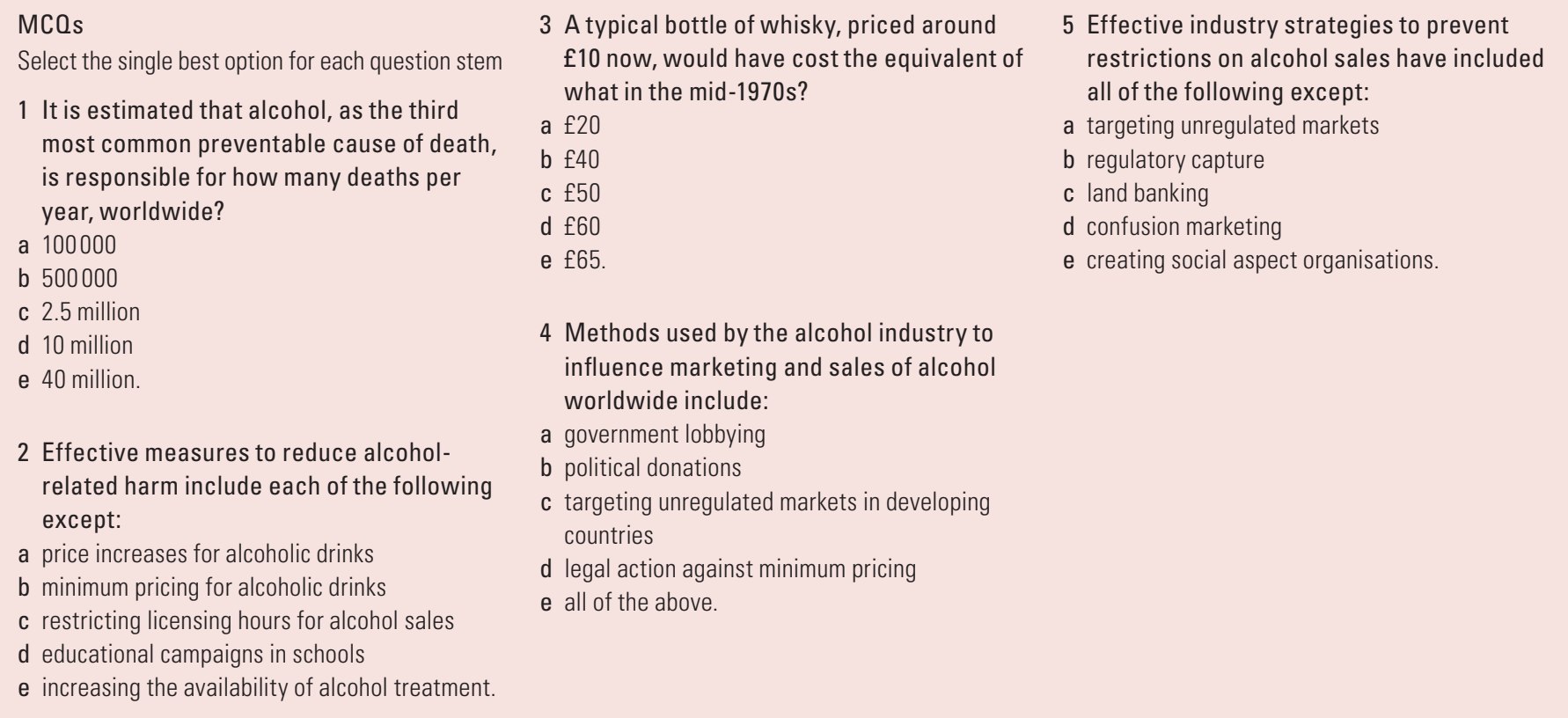

